\title{
PANORAMA DAS TEORIAS DE APRENDIZAGEM UTILIZADAS NAS PESQUISAS EM ENSINO DE FÍSICA PARA DEFICIENTES VISUAIS E OS PRODUTOS EDUCACIONAIS DA ÁREA
}

\section{Overview of learning theories used in research in teaching physics and sciences for visually disabled people and the didactical product of the area}

\author{
Willyan Mathias Formachari ${ }^{1}$ \\ Camila Maria Sitko ${ }^{2}$ \\ Narciso das Neves Soares ${ }^{3}$
}

\begin{abstract}
Resumo: Este trabalho buscou investigar quais teorias de aprendizagem são utilizadas nas pesquisas atuais em ensino de física, na área de inclusão, especificamente no que se refere à deficiência visual, bem como apresentar os tipos de recursos didáticos produzidos nestes trabalhos. Com esse propósito, realizou-se uma pesquisa de abordagem qualitativa, de caráter bibliográfico e do tipo estado da arte acerca de pesquisas que abordam as referidas temáticas. Foram analisados os artigos com classificações A1, A2, B1 e B2 publicados na Plataforma Sucupira, as dissertações do Mestrado Nacional Profissional de Ensino de Física e o banco de teses e dissertações da CAPES de 2015 a 2019. Foram encontrados 26 trabalhos, avaliados segundo o método de análise de conteúdo de Bardin, com destaques aos seguintes aspectos: metodologia, conteúdos, produto educacional e teorias de aprendizagem utilizados em cada trabalho. Constatou-se que os artigos, de maneira geral, não trazem embasamento teórico em teorias de aprendizagem, e que a maioria das teses e dissertações pesquisadas se baseia na corrente cognitivista de aprendizagem, com enfoque no sociointeracionismo de Vygotsky. Foi possível perceber também a necessidade de se ampliar as pesquisas em ensino para deficientes visuais em física, de se levar em conta outros sentidos que não o tátil para a produção de material didático, além de que tais pesquisas possam ser desenvolvidas pautadas em fundamentos teóricos de aprendizagem.
\end{abstract}

Palavras-chave: Teorias de aprendizagem. Educação inclusiva. Deficientes visuais. Ensino de física.

\footnotetext{
${ }^{1}$ Graduado em Matemática pela Universidade Federal do Pará. Discente no Mestrado Nacional Profissional em Ensino de Física da Universidade Federal do Sul e Sudeste do Pará. ORCID: https://orcid.org/0000-0001-58946278. E-mail: mathias.formachari@hotmail.com.

2 Doutora em Ensino de Ciências pela Universidade Estadual de Londrina. Técnica de Laboratório de Física na Universidade Federal do Paraná. Professora no Mestrado Nacional Profissional em Ensino de Física, e no Programa de Pós-graduação em Educação em Ciências e Matemática da Universidade Federal do Sul e Sudeste do Pará. Pesquisadora no Centro de Investigação, Desenvolvimento e Inovação do Instituto de Estudos Superiores de Fafe (CIDI-IESF). ORCID: https://orcid.org/0000-0003-4620-1388. E-mail: camilasitko@yahoo.com.br.

3 Doutor em Educação pela Universidade Federal da Bahia. Professor Associado da Faculdade de Matemática, Professor no Mestrado Nacional Profissional em Ensino de Física, e no Programa de Pós-graduação em Educação em Ciências e Matemática da Universidade Federal do Sul e Sudeste do Pará. ORCID: https://orcid.org/00000003-0331-4497. E-mail: narcisosoares52@unifesspa.edu.br.
} 
Abstract: This paper seeks to investigate the learning theories applied in current research in physics teaching in the area of inclusion, specifically regarding visual impairment, and presents the types of didactic resources produced in these works. For this purpose, qualitative, bibliographic, and state-of-the-art research was carried out on studies that address these themes. To this end, articles with A1, A2, B1 and B2 ratings, published on the Sucupira Platform, the dissertations of the National Professional Master's Degree in Physics Teaching and the CAPES thesis and dissertations database, all within the period from 2015 to 2019, were analyzed. 26 works were found, evaluated according to Bardin's content analysis method, focusing on the following aspects: methodology, content, educational product and learning theories used in each work. It was found that the articles, in general, do not have a theoretical basis in learning theories and that most of the thesis and dissertations researched are based on the cognitivist trend of learning, with a focus on Vygotsky's social interactionism. It was also possible to perceive the need to expand research in teaching physics for the visually impaired, to consider other senses than the tactile to produce didactic material and the fact that such research can be developed based on theoretical foundations of learning.

Keywords: Learning theories. Inclusive education. Visually impaired. Physics teaching.

\section{Introdução}

O debate sobre diferenças (cor, gênero, deficiência, etnia, cultura etc), que busca conscientizar a sociedade quanto ao reconhecimento, respeito e mudanças de comportamento e atitudes pela igualdade de condições de vida social, ganhou notoriedade no século XX nos mais diversos espaços de aprendizagem formais (escola e universidades) e não formais (teatro, museus, cinema, redes sociais). Nesse âmbito, daremos destaque nas diferenças relacionadas às pessoas que nasceram ou adquiriram alguma deficiência, física ou cognitiva (relativa ao processo mental de percepção, memória juízo e/ou raciocínio), em particular, os deficientes visuais, buscando perceber como as pesquisas em ensino de física estão relacionadas com as teorias de aprendizagem para tal particularidade na Educação Básica.

Pensar em alternativas metodológicas no ensino de física para pessoas deficientes visuais, cegas ou de baixa visão, tem sido um desafio constante no chão da escola, assim como da academia, tendo em vista que a observação de fenômenos é uma das principais formas de se compreender e apreender determinados conceitos de física e que, para tal, a visão tem (ou teria) importante papel no processo da aprendizagem. Entretanto, Camargo (2008) chama atenção de que certos fenômenos não observáveis visualmente podem produzir uma certa vantagem aos deficientes visuais, ao permitir uma abstração desses fenômenos, enquanto pessoas videntes necessitam de modelos representativos. Essa ponderação não implica em produzir recursos que sirvam apenas aos deficientes visuais e, sob essa perspectiva, é importante evidenciar que no contexto educacional,

superar a relação entre conhecer e ver, e reconhecer que a visão não pode ser utilizada como pré-requisito para o conhecimento de alguns fenômenos como os de física moderna, pode indicar alternativas ao ensino de física, aos quais enfocarão a deficiência visual não como limitação ou necessidade educacional especial, mas como perspectiva auxiliadora para a construção do conhecimento de física para todos os alunos. (CAMARGO, 2008, p. 25-26).

No entanto, produzir materiais didáticos que sirvam apenas aos deficientes visuais não parece fazer sentido para acompanhar aulas de física ou outras disciplinas, pois os alunos 
necessitam de recursos diversos e plurais (áudio, vídeo, texto) e espaços de aprendizagem, como a perspectiva de Desenho Universal da Aprendizagem (DUA) (MEYER; ROSE; GORDON, 2014), que busca romper com barreiras no ensino, de modo a levar em conta a diversidade e as necessidades dos alunos, de maneira geral.

\footnotetext{
Desenho Universal não é uma tecnologia direcionada apenas aos que dele necessitam; é desenhado para todas as pessoas. A ideia do Desenho Universal é, justamente, evitar a necessidade de ambientes e produtos especiais para pessoas com deficiências, assegurando que todos possam utilizar com segurança e autonomia os diversos espaços construídos e objetos. (CARLETTO; CAMBIAGHI, 2010, p. 10).
}

A criação desses espaços e objetos proporcionam motivação em pesquisas no campo da inclusão que visem a acessibilidade e o desenvolvimento de tecnologias assistivas no ensino de física para alunos cegos ou de baixa visão. Mas, qual o alcance de tais investigações?

Sendo assim, este trabalho apresenta uma pesquisa do tipo estado da arte sobre aprendizagem e ensino de física para alunos com deficiência visual, com base em artigos publicados em periódicos de Qualis A1, A2, B1 e B2 e nas teses e dissertações produzidas de 2015 a 2019, para identificar quais teorias de aprendizagem e quais meios de ensino têm sido utilizados, de modo a cooperar para a inclusão efetiva desses alunos em sala de aula. Para tanto, o artigo apresenta como aporte teórico um tópico sobre a deficiência visual e outro que traz um enfoque sintético sobre as principais abordagens de aprendizagem (comportamentalista, cognitivista e humanista). Em seguida, apresentamos a metodologia da pesquisa, os dados produzidos, os resultados e discussões e as considerações finais.

\section{A Deficiência Visual}

A preocupação com a inclusão passa a ter destaque e ser debatida com maior ênfase ao final da Segunda Guerra Mundial (1939-1945), sobretudo pela necessidade da readaptação dos soldados que ficaram com algum tipo de deficiência (AQUINO, 2018). Para além da situação instalada, ampliou-se o olhar para aqueles que nasciam com alguma deficiência, mas não eram considerados aptos a frequentarem a escola. Nessa perspectiva, em 1990, intensificou-se o debate em relação à inclusão escolar na Conferência Mundial de Educação para Todos, na Tailândia (UNICEF, 1990). Alguns anos depois, mais precisamente em 1994, ocorreu talvez o marco mais importante da luta pela inclusão, a Conferência Mundial sobre Necessidades Educativas Especiais: Acesso e Qualidade, realizada em Salamanca (Espanha), em conjunto com a UNESCO (Organização das Nações Unidas para a Educação, a Ciência e a Cultura).

A partir dos debates da Conferência de Salamanca, o Brasil, como um dos países signatários, decidiu, bem como outros países, que as escolas deveriam combater as atitudes discriminatórias e garantir acesso aos estudos às pessoas com deficiência, levando em consideração que:

O princípio que orienta esta Estrutura é o de que escolas deveriam acomodar todas as crianças independentemente de suas condições físicas, intelectuais, sociais, emocionais, linguísticas ou outras. Aquelas deveriam incluir crianças deficientes e superdotadas, crianças de rua e que trabalham, crianças de origem remota ou de população nômade, crianças pertencentes a minorias linguísticas, étnicas ou culturais, e crianças de outros grupos desavantajados ou marginalizados. (BRASIL, 1997, p. 3 ). 
Em relação às pessoas com alguma deficiência visual, o Brasil passa a garantir o ensino a Deficientes Visuais - DV como educação inclusiva, a partir da Lei nº 03/2008 - MEC, em consonância com a Lei de Diretrizes e Bases da Educação Nacional (LDB) 9.394/96 (BRASIL, 1996) que, em seu Art. 58, apresenta o seguinte texto "Entende-se por educação especial, para os efeitos desta Lei, a modalidade de educação escolar, oferecida preferencialmente na rede regular de ensino, para educandos portadores de necessidades especiais". Mediante as diferenças, estes alunos tinham agora um lugar legalmente reconhecido no espaço escolar, mas também com muito a conquistar, devido à pouca ou nenhuma condição estrutural e logística para se receber uma pessoa com deficiência visual. Assim, políticas públicas foram criadas para garantir tradutor, texto em braile, tecnologias assistivas, entre outras, e adaptações curriculares na formação docente inicial e continuada, para garantir a permanência desses alunos na Educação Básica e Superior.

Segundo o último censo, realizado em 2010 pelo Instituto Brasileiro de Geografia e Estatística (IBGE) (BRASIL, 2010), existiam até então no Brasil mais de 6,5 milhões de pessoas com alguma deficiência visual e uma boa parte dessas está presente no sistema educacional, o que evidencia necessária atenção por parte de pesquisadores em desenvolver produtos e estudos para melhor entendimento das dinâmicas pedagógicas no processo de ensino e aprendizagem de modo a incluir essas pessoas. Em função da inclusão, em várias cidades do Brasil foram criados Centros de Apoio Pedagógico (CAP) (PREFEITURA DE MARABÁ, 2019), com objetivo de garantir aos deficientes visuais o acesso a um ensino de qualidade, através de materiais de apoio pedagógico com atividades e recursos adaptados às condições do aluno e de apoio ao professor.

Para Azevedo e Santos (2014, p. 4402-1), "uma das inquietações manifestadas por professores do ensino regular ao lidar com deficientes visuais em suas classes está associada ao caráter da instrução do aluno e, aos recursos disponíveis para essa aprendizagem”. Portanto, o apoio do CAP é de elevada importância, pois para muitos professores a inclusão causa dúvidas e receio sobre como trabalhar adequadamente determinados conteúdos em sala de aula. Ainda, a tímida inserção curricular de tópicos ou atividades especializadas na graduação e na formação continuada para o ensino desses estudantes, a rotina docente com carga horária elevada, a violência, a baixa remuneração e a indisciplina de turmas lotadas são aspectos que dificultam o trabalho do professor (FERREIRA; DICKMAN, 2015). Para esses autores, de modo mais específico, em relação às dificuldades de aprendizagem de alunos cegos ou com baixa visão:

\footnotetext{
Alguns dos fatores identificados como causadores de problemas de aprendizagem entre esses alunos foram: salas lotadas, falta de recursos adaptados, falta de salas de apoio, dificuldade de adaptação do material didático, ausência de ledores, falta de professores capacitados para atender a este público, cujos efeitos foram responsáveis pelo desinteresse do aluno cego pelo estudo em geral, e, em particular, pelos desdobramentos científicos das Ciências. Estas dificuldades identificadas reiteraram que o modelo escolar vigente não tem sido capaz de atender a diversidade existente (FERREIRA; DICKMAN, 2015, p. 2).
}

A visão é responsável pelo contato visual com o mundo desde os primeiros meses de vida de uma pessoa. Estimula a percepção de tudo que está ao redor, permitindo assim, associarse aos sons e imagens. Azevedo e Santos (2014, p. 4402-2) afirmam que "Nossas impressões acerca do mundo ao nosso redor se manifestam de modo majoritariamente visual. A visão é responsável por pelo menos $80 \%$ das informações adquiridas pelo ser humano". Em 
contrapartida, a cegueira afeta a capacidade de perceber cor, tamanho, distância, forma, posição ou movimento, signos e instrumentos, levando o indivíduo com deficiência visual a desenvolver e ampliar outros sentidos que permitam sua interação com o mundo. No contexto escolar, a adaptação precisa ocorrer dos dois lados, tanto por parte do aluno deficiente visual quanto do sistema escolar, que ambos devem se preparar adequadamente e com o devido suporte de políticas públicas, em conformidade com a legislação vigente.

\section{Abordagens Teóricas de Aprendizagem}

O ambiente escolar é constituído de uma tríade, cujos conceitos interligados e bem estruturados podem promover o desenvolvimento escolar com sucesso: o aluno, o professor e a situação de aprendizagem (ou teoria de aprendizagem).

Compreender o modo como os alunos aprendem e as condições necessárias para essa aprendizagem, bem como determinar o papel do professor nesse processo, são elementos centrais das teorias de aprendizagem. O papel norteador dessas teorias possibilita ao professor constituir conhecimentos, competências, habilidades e instrumentos avaliativos que vão auxiliá-lo nas decisões sobre qual melhor estratégia metodológica de ensino e quais recursos didáticos usar em sala de aula.

Os estudos do campo da psicologia educacional, com base em pesquisas experimentais, concebem teorias que procuram explicar, por meio de diferentes enfoques, como os indivíduos aprendem, como se processa o seu desenvolvimento mental e como se estruturam os modelos institucionais que implicam, entre outros, na organização do currículo escolar. São apontadas como principais abordagens teóricas de aprendizagem a Behaviorista/Comportamentalista, a Cognitivista e a Humanista (MOREIRA, 1999). O mapa conceitual da Figura 01 ilustra um panorama geral das teorias de aprendizagem que, por sua vez, geram teorias com conceitos que se relacionam, formando princípios bem estabelecidos, necessários para a compreensão das concepções filosóficas das três abordagens teóricas, a serem tratadas mais adiante.

Figura 01 - Mapa conceitual das teorias de aprendizagem

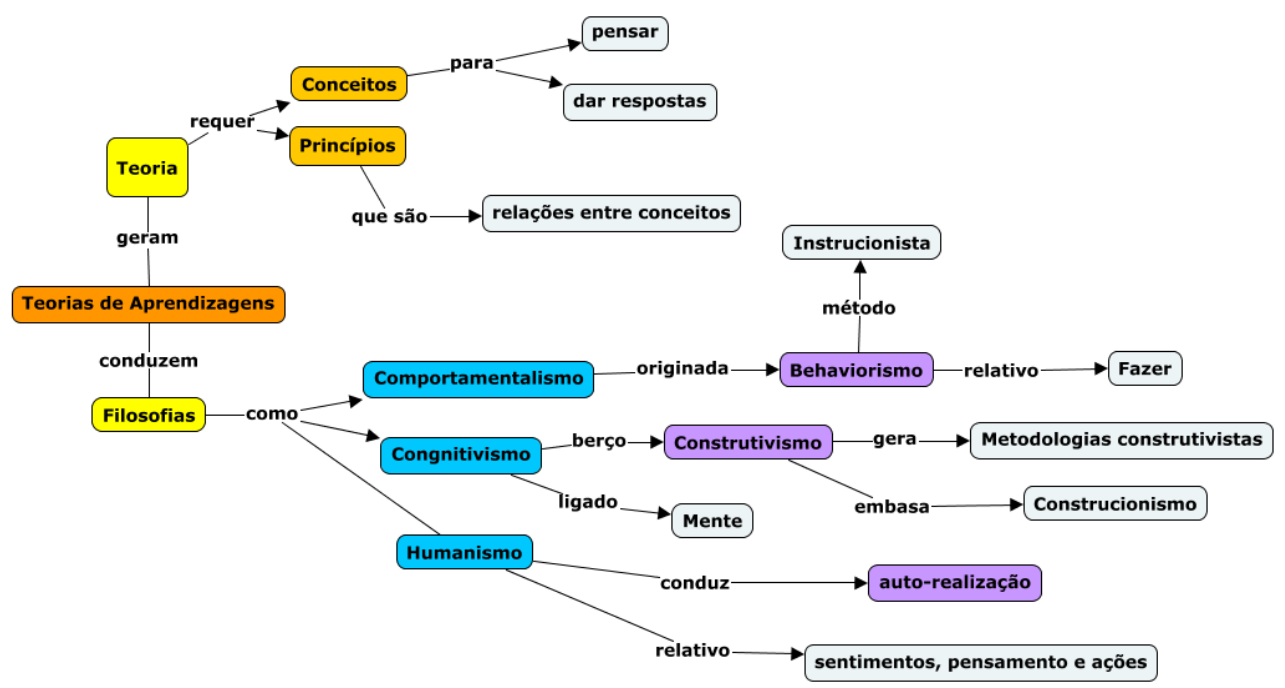

Fonte: Elaborado pelos autores. 
As teorias da abordagem Behaviorista/Comportamentalista entendem o aprendiz como um ser que responde a estímulos do meio exterior, não levando em consideração o que ocorre dentro de sua mente durante o processo. A aprendizagem é interpretada somente como mudança de comportamento. O principal teórico dessa linhagem é Frederic Skinner, famoso por seus estudos do condicionamento operante, com relação ao estímulo-resposta e reforço. Nessa teoria, acredita-se que o comportamento é condicionado pelas consequências, ou seja, se elas forem boas, a frequência da resposta irá aumentar, se não, a frequência de respostas irá diminuir. Em outras palavras, sua teoria consiste no comportamento observável, ou seja, para ele, não interessam os processos intermediários entre estímulos e respostas. Skinner atua no controle daquilo que pode ser observado (MOREIRA, 1999).

Já a abordagem cognitivista enfatiza os processos de cognição, compreensão, transformação, armazenamento e uso da informação, ou seja, ocupa-se dos processos mentais. Os principais teóricos dessa corrente são Jerome Bruner, com sua Teoria Construtivista da aprendizagem em espiral, Johnson-Laird e os modelos mentais, Jean Piaget, famoso por seus estudos de Epistemologia Genética, David Ausubel, que definiu a Aprendizagem Significativa, e Vygotsky (1896-1934), conhecido por sua Teoria Sociointeracionista.

Johnson-Laird considera que os modelos mentais, juntamente com as imagens, são importantes para a compreensão humana. Para ele, os eventos externos são traduzidos em eventos internos através dos mapas mentais, ocasionando assim a compreensão do mundo ao redor do indivíduo (JOHNSON-LAIRD, 1983).

Piaget é considerado por alguns autores como um dos pioneiros da perspectiva construtivista da cognição humana. Sua teoria de aprendizagem está relacionada com a construção de esquemas de assimilação do indivíduo, que vão evoluindo conforme sua idade. Nessa teoria, são definidos quatro períodos do desenvolvimento cognitivo humano: o primeiro estágio é o sensório-motor, que vai do nascimento até os dois anos; o segundo é o préoperacional, que dura dos dois aos seis anos; o terceiro é o operacional-concreto, que vai dos sete aos doze anos; e, por último, o operacional-formal, que vai da adolescência à vida adulta (MOREIRA, 1999).

Já Ausubel estabeleceu a teoria da aprendizagem significativa. De acordo com essa teoria, a aprendizagem é significativa à medida que o novo conteúdo é incorporado às estruturas de conhecimento de um aluno e adquire significado para ele a partir da relação com seu conhecimento prévio, existente na sua estrutura cognitiva. Mas para que isso ocorra, é necessário que haja predisposição do aluno em aprender. Nesse sentido, é necessário que haja subsunçores, que são esses conhecimentos prévios, ou que sejam utilizados materiais potencialmente significativos, de forma que a situação de aprendizagem faça sentido para o aluno (MOREIRA, 1999).

Por fim, na vertente cognitivista, temos Vygotsky e sua teoria sociointeracionista. Para Vygostsky, o crescimento dos processos mentais do indivíduo inicia-se pelos processos sociais. Vygotsky acreditava na interação entre os indivíduos e o seu contexto, e não na observação individual de cada um (MOREIRA, 1999). Para ele, o desenvolvimento cognitivo nada mais é que a conversão de relações sociais em funções mentais. Em outras palavras, em sua estrutura cognitiva, o sujeito reconstrói conhecimentos que já foram construídos externamente em um contexto sócio-histórico e cultural.

O enfoque humanista vê o aprendiz em sua totalidade. Nessa abordagem, o importante é a autorrealização, o crescimento pessoal. Os principais teóricos são Carl Rogers e a Teoria da Personalidade, George Kelly e os construtos pessoais, e especialmente Paulo Freire, com sua Pedagogia Libertária e Educação Emancipadora. Freire visa a formação do sujeito de maneira 
integral, para que possa atuar criticamente e transformar a sociedade ao seu redor. Nesse sentido, a aprendizagem e a produção do conhecimento ocorrem através do processo de diálogo das experiências vividas, traduzidas como realidade social, cultural, política e afetiva com as situações de aprendizagem mediadas pelo educador (FREIRE, 1997).

O conhecimento dessas abordagens teóricas por parte dos professores pode proporcionar melhoria na qualidade do ensino, bem como sobre utilização de métodos, técnicas e recursos didáticos, que proporcionam ao aluno alcançar melhor desempenho na aprendizagem. Alguns trabalhos apresentam resultados do uso de tais abordagens, como o de Azevedo e Santos (2014) e o uso da teoria piagetiana no ensino de física para deficientes visuais; Gaspar e Monteiro, que fizeram uso da teoria sociointeracionista de Vygotsky para aulas experimentais de física; Jesus e Amorim (2019), e o uso da aprendizagem significativa de Ausubel para ensino de física de partículas; Moreira e Pinto (2003), que utilizaram a teoria dos modelos mentais de JohnsonLaird para sanar dificuldades na aprendizagem da Lei de Ampère; e Solino e Gehlen (2015), que utilizaram a perspectiva freireana para o trabalho com o ensino de ciências/física por investigação.

\title{
4 Metodologia da pesquisa
}

A abordagem metodológica utilizada foi a qualitativa, visto que nela se estabelece o alicerce para o encontro entre o pesquisador e o objeto pesquisado e por apresentar:

\footnotetext{
Um enfoque investigativo, cuja preocupação primordial é compreender o fenômeno, descrever o objeto de estudo, interpretar seus valores e relações, não dissociando o pensamento da realidade dos atores sociais e onde o pesquisador e pesquisado são sujeitos recorrentes, e por consequência, ativos no desenvolvimento da investigação científica. (LIMA, 2003, p. 7).
}

Para identificar quais teorias de aprendizagem são mais aplicadas e quais métodos de ensino aparecem de modo recorrente em pesquisas sobre a aprendizagem de física de alunos com deficiência visual, realizamos uma pesquisa do tipo estado da arte. As pesquisas do tipo estado da arte,

\begin{abstract}
Definidas como de caráter bibliográfico, [...] parecem trazer em comum o desafio de mapear e de discutir uma certa produção acadêmica em diferentes campos do conhecimento, tentando responder que aspectos e dimensões vêm sendo destacados e privilegiados em diferentes épocas e lugares, de que formas e em que condições têm sido produzidas certas dissertações de mestrado, teses de doutorado, publicações em periódicos e comunicações em anais de congressos e de seminários. (FERREIRA, 2002, p. 257).
\end{abstract}

A pesquisa tomou três frentes de consulta: 1) artigos de revistas científicas brasileiras de classificação A1, A2, B1, B2, da área de Ensino; 2) Dissertações defendidas pelo Mestrado Nacional Profissional em Ensino de Física (MNPEF), ligado à Sociedade Brasileira de Física (SBF) e 3) Catálogo de Teses e Dissertações (CTD) da CAPES (Coordenação de Aperfeiçoamento de Pessoal de Nível Superior). O período de publicação determinado foi de 2015 a 2019, por coincidir com as primeiras defesas de dissertação do Mestrado Nacional Profissional em Ensino de Física (MNPEF). 
Outra preocupação foi quanto aos descritores, que deveriam estar relacionados com a temática pesquisada. Portanto, foram considerados os seguintes termos de busca no momento da pesquisa: ensino de física para alunos com deficiência visual, ensino de física para alunos de baixa visão, revisão bibliográfica (das teorias de aprendizagem) e ensino de física através de recursos lúdicos. Alguns desses temas deveriam estar contidos no corpo do artigo.

Para o tratamento dos dados encontrados e selecionados, no intuito de se trabalhar com as diferentes fontes de forma rigorosa e subjetiva, optou-se por tomar como norteador as técnicas de análise de conteúdo propostas por Bardin (2011), que a autora designa como

\begin{abstract}
um conjunto de técnicas de análise das comunicações visando a obter, por procedimentos sistemáticos e objetivos de descrição do conteúdo das mensagens, indicadores (quantitativos ou não) que permitam a inferência de conhecimentos relativos às condições de produção/recepção (variáveis inferidas) destas mensagens. (BARDIN, 2011, p. 47).
\end{abstract}

Assim, o método de análise de Bardin (2011) é dividido em três fases de implantação, que são: 1) pré-análise, quando se discute a organização e sistematização das ideias; 2) a exploração do material, quando se realiza a composição e classificação do material, e, 3) o tratamento dos resultados, com interpretação e inferência dos dados. Esta pesquisa segue esses três passos para seu desenvolvimento, pautada em evidências científicas do tratamento da informação, buscando assim constituir um panorama dos teóricos de aprendizagem utilizados no ensino de física para alunos com algum tipo de deficiência visual da forma mais assertiva possível.

\title{
5 Os dados coletados
}

Como já mencionado, foram utilizadas três fontes de dados, os artigos da área de Ensino e Educação, dissertações defendidas no âmbito do MNPEF, e o Catálogo de Teses e Dissertações da CAPES. No total, foram selecionados 26 trabalhos, sendo 11 artigos, 12 dissertações e três teses.

O momento inicial da coleta de dados foi realizado com base nos artigos. O primeiro passo para o mapeamento dos artigos científicos foi a classificação das revistas. Desse modo, foram selecionados 11 artigos que se adequavam aos parâmetros pré-estabelecidos. No quadro 1 são apresentadas as pesquisas encontradas, que abarcam, no item Métodos de Pesquisa, as seguintes referências metodológicas: Revisão Bibliográfica (RB), Pesquisa Qualitativa (PQ), e Produção de Material Didático (PMD). Além disso, são apresentadas também no quadro características como: as teorias de aprendizagem nas quais a atividade foi baseada, o conteúdo de física explorado, a revista em que o artigo foi publicado e o produto educacional trabalhado. 
Quadro 1 - Artigos selecionados

\begin{tabular}{|c|c|c|c|c|c|}
\hline Título $^{4}$ & $\begin{array}{c}\text { Teoria de } \\
\text { aprendizagem }\end{array}$ & $\begin{array}{l}\text { Método } \\
\text { de } \\
\text { pesquisa }\end{array}$ & $\begin{array}{l}\text { Conteúdo } \\
\text { explorado }\end{array}$ & $\begin{array}{c}\text { Revista } \\
\text { (Qualis) }\end{array}$ & $\begin{array}{c}\text { Produto } \\
\text { Educacional }\end{array}$ \\
\hline $\begin{array}{l}\text { Formamos professores para a } \\
\text { educação inclusiva? Análise de } \\
\text { publicações sobre formação de } \\
\text { professores de Ciências/Biologia }\end{array}$ & Não apresentou & $\mathrm{RB}$ & $\begin{array}{c}\text { Não } \\
\text { apresentou }\end{array}$ & $\begin{array}{c}\text { Revista } \\
\text { Brasileira de } \\
\text { Ensino de } \\
\text { Ciência e } \\
\text { Tecnologia (A2 } \\
\text { ensino) }\end{array}$ & \\
\hline $\begin{array}{l}\text { Estudos Nacionais Sobre o } \\
\text { Ensino para Cegos: uma Revisão } \\
\text { Bibliográfica }\end{array}$ & Não apresentou & $\mathrm{RB}$ & $\begin{array}{c}\text { Não } \\
\text { apresentou }\end{array}$ & $\begin{array}{l}\text { Revista } \\
\text { Brasileira } \\
\text { Educação } \\
\text { Especial (A1 } \\
\text { ensino) }\end{array}$ & \\
\hline $\begin{array}{l}\text { Acessibilidade para estudantes } \\
\text { cegos e baixa visão: análise dos } \\
\text { objetos educacionais digitais de } \\
\text { física }\end{array}$ & Não apresentou & $\mathrm{RB}$ & $\begin{array}{c}\text { Não } \\
\text { apresentou }\end{array}$ & $\begin{array}{l}\text { Revista } \\
\text { Educação } \\
\text { Especial (A2 } \\
\text { ensino) }\end{array}$ & \\
\hline $\begin{array}{l}\text { O Ensino de Física e as Políticas } \\
\text { Públicas da Educação Inclusiva: } \\
\text { o que se tem feito? }\end{array}$ & Não apresentou & $\mathrm{RB}$ & $\begin{array}{c}\text { Não } \\
\text { apresentou }\end{array}$ & $\begin{array}{l}\text { Revista Tecné, } \\
\text { Episteme y } \\
\text { Didaxis: TED } \\
\text { (B2 ensino) }\end{array}$ & \\
\hline $\begin{array}{l}\text { Panorama de publicações em } \\
\text { ensino de ciências e educação } \\
\text { inclusivas: o que tem sido } \\
\text { produzido }\end{array}$ & Não apresentou & $\mathrm{RB}$ & $\begin{array}{c}\text { Não } \\
\text { apresentou }\end{array}$ & $\begin{array}{c}\text { Revista } \\
\text { Brasileira de } \\
\text { Ensino de } \\
\text { ciência e } \\
\text { tecnologia (A2 } \\
\text { ensino) }\end{array}$ & \\
\hline 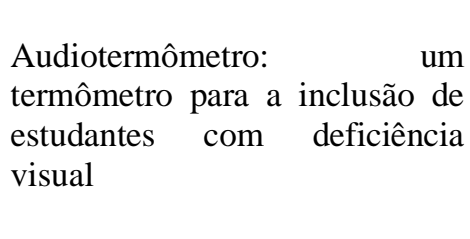 & Não apresentou & PMD & $\begin{array}{l}\text { Termometr } \\
\text { ia } \\
\text { e } \\
\text { Calorimetr } \\
\text { ia }\end{array}$ & $\begin{array}{l}\text { Revista } \\
\text { Brasileira de } \\
\text { Ensino de } \\
\text { Física (A1 } \\
\text { ensino) }\end{array}$ & $\begin{array}{l}\text { Termômetro } \\
\text { com medidas } \\
\text { audíveis }\end{array}$ \\
\hline $\begin{array}{l}\text { Lâminas em alto-relevo para } \\
\text { ensinar fenômenos ondulatórios } \\
\text { a deficientes visuais }\end{array}$ & Não apresentou & PMD & $\begin{array}{l}\text { Ondas e } \\
\text { Fenômeno } \\
\text { s } \\
\text { ondulatóri } \\
\text { os }\end{array}$ & $\begin{array}{l}\text { Revista } \\
\text { Brasileira de } \\
\text { Ensino de } \\
\text { Física (A1 } \\
\text { ensino) }\end{array}$ & $\begin{array}{l}\text { Lâminas Em } \\
\text { Alto Relevo }\end{array}$ \\
\hline $\begin{array}{l}\text { Avaliação de um kit didático que } \\
\text { reproduz tatilmente ilustrações } \\
\text { no ensino de Física }\end{array}$ & Não apresentou & PMD & $\begin{array}{l}\text { Óptica } \\
\text { geométrica } \\
\text {, Conceitos }\end{array}$ & $\begin{array}{l}\text { Revista } \\
\text { educação }\end{array}$ & $\begin{array}{l}\text { Kitfis (Kit } \\
\text { Didático } \\
\text { Tátil) }\end{array}$ \\
\hline
\end{tabular}

\footnotetext{
${ }^{4}$ É importante mencionar que as referências de todos os trabalhos apresentados nos quadros deste artigo estão disponíveis nas referências bibliográficas.
} 


\begin{tabular}{|l|l|l|c|c|c|}
\hline & & & $\begin{array}{c}\text { de força, } \\
\text { resistência } \\
\text { elétrica. }\end{array}$ & $\begin{array}{c}\text { especial (A2 } \\
\text { ensino) }\end{array}$ & \\
\hline $\begin{array}{l}\text { História Oral: um Método para } \\
\text { Investigar o Ensino de Física } \\
\text { para Estudantes Cegos }\end{array}$ & Não apresentou & PQ & $\begin{array}{c}\text { Não } \\
\text { apresentou }\end{array}$ & $\begin{array}{c}\text { Revista } \\
\text { Brasileira de } \\
\text { Educação } \\
\text { Especial (A2 } \\
\text { ensino) }\end{array}$ & - \\
\hline $\begin{array}{l}\text { Utilizando a audiodescrição } \\
\text { como um recurso de ensino }\end{array}$ & Não apresentou & PQ & $\begin{array}{c}\text { Conservaç } \\
\text { ão de } \\
\text { Energia }\end{array}$ & $\begin{array}{c}\text { Revista Ibero- } \\
\text { Americana de } \\
\text { Estudos em } \\
\text { Educação (B1 } \\
\text { ensino) }\end{array}$ & $\begin{array}{c}\text { Sequência } \\
\text { didática e } \\
\text { audiodescriç } \\
\text { âo }\end{array}$ \\
\hline $\begin{array}{l}\text { Formação de Professores: ensino } \\
\text { de física para cegos através de } \\
\text { atividades em relevo }\end{array}$ & Não apresentou & PQ & $\begin{array}{c}\text { Moviment } \\
\text { o Retilíneo } \\
\text { Uniforme } \\
\text { /exercício } \\
\text { de } \\
\text { Moviment } \\
\text { o Retilíneo } \\
\text { Uniforme } \\
\text { mente } \\
\text { Variado }\end{array}$ & $\begin{array}{c}\text { Interações (B2 } \\
\text { educação) }\end{array}$ & $\begin{array}{c}\text { Gráfico em } \\
\text { alto-relevo }\end{array}$ \\
\\
\hline
\end{tabular}

Fonte: Elaborado pelos autores.

$\mathrm{Na}$ segunda parte da pesquisa, realizamos o mapeamento das dissertações presentes no site da Sociedade Brasileira de Física (SBF), resultantes do Mestrado Nacional Profissional em Ensino de Física (MNPEF), desde sua criação, em 2013, até 2019. Nessa busca, encontramos 509 dissertações. Dessas, apenas sete com pesquisas voltadas para o ensino de física para alunos com deficiência visual, como mostra o quadro 2. Faz-se observar que os itens das colunas são praticamente os mesmos que os apresentados para os artigos, para fins de comparação, mudando apenas a penúltima coluna, que no lugar da revista de publicação, agora estão as instituições de defesa, e o item metodologia aparece como referência metodológica, além da Produção de Material Didático (PMD), o método Adaptação de Material Didático (AMD). Continua também a coluna Produto Educacional, que é uma exigência para as dissertações do mestrado profissional. 
Quadro 02 - Dissertações do MNPEF

\begin{tabular}{|c|c|c|c|c|c|}
\hline Título & $\begin{array}{c}\text { Teoria de } \\
\text { aprendizagem }\end{array}$ & $\begin{array}{l}\text { Método } \\
\text { de } \\
\text { pesquisa }\end{array}$ & $\begin{array}{l}\text { Conteúdo } \\
\text { explorado }\end{array}$ & Polo/ano & $\begin{array}{c}\text { Produto } \\
\text { Educacional }\end{array}$ \\
\hline $\begin{array}{l}\text { Kit de brinquedos: } \\
\text { lâminas em alto relevo } \\
\text { para o ensino de ondas e } \\
\text { fenômenos ondulatórios } \\
\text { a deficientes visuais }\end{array}$ & $\begin{array}{c}\text { A teoria de } \\
\text { aprendizagem } \\
\text { significativa de } \\
\text { Ausubel }\end{array}$ & PMD & $\begin{array}{c}\text { Ondas e } \\
\text { Fenômenos } \\
\text { Ondulatórios }\end{array}$ & $\begin{array}{l}\text { Polo 09: } \\
\text { UFERSA } \\
\text { (2018) }\end{array}$ & $\begin{array}{l}\text { Lâminas em } \\
\text { Alto Relevo }\end{array}$ \\
\hline $\begin{array}{l}\text { O uso do laboratório de } \\
\text { ciências para o ensino de } \\
\text { física no ensino } \\
\text { fundamental com uma } \\
\text { abordagem adaptada para } \\
\text { deficientes visuais: uma } \\
\text { proposta inclusiva }\end{array}$ & $\begin{array}{c}\text { Teoria de } \\
\text { Piaget da } \\
\text { experimentação }\end{array}$ & AMD & Óptica geométrica & $\begin{array}{l}\text { Polo 37: } \\
\text { UFPA (2017) }\end{array}$ & $\begin{array}{l}\text { Experimentos } \\
\text { didáticos } \\
\text { através de } \\
\text { maquetes } \\
\text { táteis }\end{array}$ \\
\hline $\begin{array}{l}\text { Produção e aplicação de } \\
\text { maquetes para deficientes } \\
\text { visuais como ferramenta } \\
\text { para aulas de astronomia }\end{array}$ & $\begin{array}{c}\text { Teoria de } \\
\text { Vygotsky da } \\
\text { interação social }\end{array}$ & PMD & $\begin{array}{l}\text { Astronomia: Terra } \\
\text { e Corpos Celestes }\end{array}$ & $\begin{array}{l}\text { Polo 44: } \\
\text { UESC (2017) }\end{array}$ & $\begin{array}{c}\text { Maquetes } \\
\text { ilustrativas } \\
\text { táteis }\end{array}$ \\
\hline $\begin{array}{l}\text { Experimentos de física } \\
\text { adaptados para o ensino } \\
\text { de estática dos fluidos a } \\
\text { alunos com cegueira do } \\
\text { ensino fundamental: } \\
\text { teorema de Stevin, vasos } \\
\text { comunicantes e princípio } \\
\text { de pascal }\end{array}$ & $\begin{array}{c}\text { Teoria de } \\
\text { Piaget da } \\
\text { experimentação }\end{array}$ & PMD & $\begin{array}{l}\text { Estática dos } \\
\text { fluidos }\end{array}$ & $\begin{array}{l}\text { Polo 29: } \\
\text { UNIFESSPA } \\
(2016)\end{array}$ & $\begin{array}{c}\text { Experimentos } \\
\text { de } \\
\text { hidrostática } \\
\text { táteis }\end{array}$ \\
\hline $\begin{array}{llr}\text { O } & \text { ensino } & \text { de } \\
\text { eletromagnetismo } & \text { para } \\
\text { alunos } & \text { com deficiência } \\
\text { visual } & & \end{array}$ & $\begin{array}{c}\text { Teoria de } \\
\text { Vygotsky da } \\
\text { interação social }\end{array}$ & PMD & Eletromagnetismo & $\begin{array}{l}\text { Polo 02: UFG } \\
\quad \text { (2015) }\end{array}$ & $\begin{array}{l}\text { Maquetes- } \\
\text { táteis }\end{array}$ \\
\hline $\begin{array}{l}\text { O ensino de óptica para } \\
\text { cegos na perspectiva de } \\
\text { compreender a luz a } \\
\text { partir do som }\end{array}$ & $\begin{array}{l}\text { Aprendizagem } \\
\text { significativa }\end{array}$ & PMD & Óptica & $\begin{array}{l}\text { Polo 29: } \\
\text { UNIFESSPA- } \\
2018\end{array}$ & $\begin{array}{l}\text { Sequência } \\
\text { Didática com } \\
\text { materiais } \\
\text { sonoros e } \\
\text { táteis }\end{array}$ \\
\hline $\begin{array}{l}\text { Desenvolvimento } \\
\text { aplicação de uma } \\
\text { maquete sobre as leis de } \\
\text { Kepler para inclusão de } \\
\text { alunos portadores de } \\
\text { deficiência visual no } \\
\text { ensino de física }\end{array}$ & $\begin{array}{c}\text { Teoria de } \\
\text { Vygotsky da } \\
\text { interação social }\end{array}$ & PMD & Leis de Kepler & $\begin{array}{l}\text { Polo 16: } \\
\text { UNESP/2015 }\end{array}$ & $\begin{array}{l}\text { Maquete } \\
\text { tátil-visual }\end{array}$ \\
\hline
\end{tabular}

Fonte: Elaborado pelos autores.

$\mathrm{Na}$ terceira etapa, pesquisamos as teses e dissertações no âmbito do Catálogo de Teses e Dissertações da CAPES. Dos milhares de arquivos disponíveis na plataforma, somente oito 
atenderam aos nossos critérios de busca (é importante mencionar que os trabalhos do quadro 2 também estavam presentes no catálogo da CAPES, e, assim, não foram incluídos no terceiro quadro novamente), conforme apresentados no quadro 3, com os mesmos itens de colunas do quadro 2, sendo que no lugar do polo aparece agora a instituição e no item Metodologia de Pesquisa apresentam-se outros elementos, como análise documental, entrevista, atividade multissensorial e observações.

Quadro 03 - Catálogo de Teses e Dissertações da CAPES

\begin{tabular}{|c|c|c|c|c|c|}
\hline Título & $\begin{array}{l}\text { Teoria de } \\
\text { aprendizage } \\
\mathbf{m}\end{array}$ & $\begin{array}{l}\text { Método de } \\
\text { pesquisa }\end{array}$ & $\begin{array}{l}\text { Conteúdo } \\
\text { explorado }\end{array}$ & $\begin{array}{c}\text { Instituição } \\
\text { /ano/tipo }\end{array}$ & $\begin{array}{c}\text { Produto } \\
\text { Educacional }\end{array}$ \\
\hline $\begin{array}{l}\text { Formação de professores } \\
\text { de matemática, física e } \\
\text { química na perspectiva da } \\
\text { inclusão de estudantes } \\
\text { com deficiência visual: } \\
\text { análise de uma } \\
\text { intervenção realizada em } \\
\text { Rondônia }\end{array}$ & $\begin{array}{l}\text { Teoria de } \\
\text { Vygotsky da } \\
\text { interação } \\
\text { social }\end{array}$ & $\begin{array}{l}\text { Abordagem } \\
\text { qualitativa; } \\
\text { Análise } \\
\text { documental }\end{array}$ & Fenômenos & $\begin{array}{l}\text { UFMT - } \\
\text { UEA - } \\
\text { UFPA/201 } \\
5 / \text { Tese }\end{array}$ & $\begin{array}{c}\text { Vários produtos, } \\
\text { entre eles: Tabela } \\
\text { Periódica com } \\
\text { escrita em braile; } \\
\text { Maquete; } \\
\text { Plano cartesiano } \\
\text { em madeira } \\
\text { (Multiplano); } \\
\text { Kit de Geometria } \\
\text { Plana }\end{array}$ \\
\hline $\begin{array}{l}\text { Análise da socialização } \\
\text { entre videntes e cegos } \\
\text { durante aulas de física em } \\
\text { uma escola polo de Santo } \\
\text { André }\end{array}$ & $\begin{array}{l}\text { Teoria de } \\
\text { Vygotsky da } \\
\text { interação } \\
\text { social }\end{array}$ & Entrevista & $\begin{array}{l}\text { Conceitos } \\
\text { físicos }\end{array}$ & $\begin{array}{l}\text { UFABC- } \\
\text { 2015/ } \\
\text { Dissertação }\end{array}$ & \\
\hline $\begin{array}{l}\text { Ensino de física para } \\
\text { estudantes cegos e } \\
\text { políticas públicas: } \\
\text { barreiras que dificultam a } \\
\text { inserção de um recurso } \\
\text { didático inédito na escola } \\
\text { inclusiva }\end{array}$ & $\begin{array}{l}\text { Informação } \\
\text { não } \\
\text { encontrada }\end{array}$ & PMD & Mecânica & $\begin{array}{l}\text { PUC Minas } \\
\text { - 2019/ } \\
\text { Tese }\end{array}$ & \\
\hline $\begin{array}{l}\text { Utilização de recursos de } \\
\text { matemática inclusiva no } \\
\text { ensino de Física para } \\
\text { pessoas com deficiência } \\
\text { visual }\end{array}$ & $\begin{array}{c}\text { Aprendizagem } \\
\text { significativa } \\
\text { de Ausubel e } \\
\text { nos princípios } \\
\text { da } \\
\text { Defectologia } \\
\text { de Vygotsky }\end{array}$ & PMD & $\begin{array}{l}2^{\mathrm{a}} . \text { Lei de } \\
\text { Newton e } \\
\text { força de } \\
\text { atrito }\end{array}$ & $\begin{array}{l}\text { UNB/2017/ } \\
\text { Dissertação }\end{array}$ & $\begin{array}{l}\text { Confecção da } \\
\text { maquete tátil e do } \\
\text { carrinho com } \\
\text { vetores }\end{array}$ \\
\hline $\begin{array}{l}\text { Atividades } \\
\text { multissensoriais para o } \\
\text { ensino de física }\end{array}$ & $\begin{array}{c}\text { Multissensoria } \\
\text { lidade de } \\
\text { Soller (1999) e } \\
\text { organização } \\
\text { do } \\
\text { pensamento } \\
\text { no processo de }\end{array}$ & $\begin{array}{l}\text { Atividade } \\
\text { multissensor } \\
\text { ial }\end{array}$ & $\begin{array}{l}\text { Fenômenos } \\
\text { físicos } \\
\text { (ondas) }\end{array}$ & $\begin{array}{l}\text { USP/2016/ } \\
\text { Tese }\end{array}$ & $\begin{array}{l}\text { Sequência } \\
\text { didática: } \\
\text { atividades } \\
\text { multissensoriais } \\
\text { (experiência } \\
\text { realizada por uma } \\
\text { corda com a ponta } \\
\text { fixa) }\end{array}$ \\
\hline
\end{tabular}




\begin{tabular}{|c|c|c|c|c|c|}
\hline & $\begin{array}{l}\text { significação } \\
\text { de Vygotsky }\end{array}$ & & & & \\
\hline $\begin{array}{l}\text { Ensino de Astronomia na } \\
\text { Perspectiva da Inclusão } \\
\text { de Deficientes Visuais } \\
\text { em Aulas de Física do } \\
\text { Ensino Médio }\end{array}$ & $\begin{array}{l}\text { Teoria } \\
\text { Freiriana de } \\
\text { ensino }\end{array}$ & PMD & $\begin{array}{c}\text { Astronomia: } \\
\text { origem do } \\
\text { Universo }\end{array}$ & $\begin{array}{l}\text { UFF/2016/ } \\
\text { Dissertação }\end{array}$ & $\begin{array}{c}\text { Sequência } \\
\text { didática } \\
\text { multissensorial }\end{array}$ \\
\hline $\begin{array}{l}\text { Ensino de Física para } \\
\text { alunos com deficiência } \\
\text { visual: o processo de } \\
\text { ensino-aprendizagem nos } \\
\text { ambientes escolares das } \\
\text { salas de aula regular e de } \\
\text { recursos }\end{array}$ & $\begin{array}{l}\text { Teoria de } \\
\text { Vygotsky da } \\
\text { interação } \\
\text { social }\end{array}$ & Entrevista & $\begin{array}{l}\text { Fenômenos } \\
\text { físicos }\end{array}$ & $\begin{array}{c}\text { UNESP/20 } \\
16 / \\
\text { Dissertação }\end{array}$ & \\
\hline $\begin{array}{l}\text { Metodologias no ensino } \\
\text { de física para deficientes } \\
\text { visuais utilizando' a } \\
\text { cartografia tátil }\end{array}$ & $\begin{array}{c}\text { Sócio } \\
\text { interacionista } \\
\text { de Vygotsky; } \\
\text { O } \\
\text { construtivismo } \\
\text { de Piaget; } \\
\text { Aprendizagem } \\
\text { significativa } \\
\text { de Ausubel; } \\
\text { Modelos } \\
\text { Mentais de } \\
\text { Johnson Laird }\end{array}$ & $\begin{array}{c}\text { RB } \\
\text { Entrevista } \\
\text { Observações }\end{array}$ & $\begin{array}{c}\text { Eletromagne } \\
\text { tismo }\end{array}$ & $\begin{array}{c}\text { UFAC/201 } \\
7 / \\
\text { Dissertação }\end{array}$ & $\begin{array}{l}\text { Apostila com } \\
\text { passo a passo da } \\
\text { construção de } \\
\text { materiais } \\
\text { manipuláveis }\end{array}$ \\
\hline
\end{tabular}

Fonte: Elaborado pelos autores.

\section{Resultados e discussões}

A pesquisa foi desenvolvida com intuito de apresentar o que se tem produzido no campo da inclusão de alunos cegos de 2015 a 2019 no ensino de Física, indicando teorias de aprendizagem, metodologia, conteúdo envolvido, ano, revista e classificação na Plataforma Sucupira de cada artigo, ou, no caso das dissertações, instituição, e, para as dissertações do MNPEF, produto educacional e polo. De forma geral, observou-se uma certa escassez de produções que relacionam o ensino de Física (ou ciência), para alunos com alguma deficiência visual, nas três bases de dados.

Com relação aos dados encontrados na pesquisa de artigos, somente 11 trabalhavam com a temática da inclusão voltada para alunos com alguma deficiência visual, sendo que cinco desses são pesquisas bibliográficas, como a realizada neste artigo, e um se baseava em uma entrevista, o que resume as publicações de experiências e materiais elaborados para o ensino de física a apenas cinco artigos.

Olhando para os conteúdos trabalhados, seis artigos são apenas de revisão bibliográfica. Dois artigos trabalham com óptica e ondulatória (sendo que um deles trabalha com conteúdos adicionais), um trata de termometria e calorimetria, um trata de cinemática e um de conservação de energia. Nenhum destaque foi dado a assuntos como física moderna ou eletromagnetismo, o que é de se estranhar dado que esses assuntos são, conforme Camargo (2008), de maior facilidade para apreensão conceitual por alunos cegos ou de baixa visão. Com relação aos cinco 


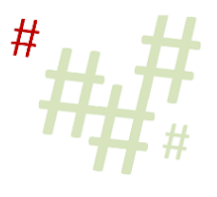

produtos educacionais destacados em alguns artigos, três eram táteis e dois eram sonoros, sendo que os cinco artigos que apresentaram algum conteúdo de física, também apresentaram produto educacional.

Identificamos também quais teorias de aprendizagem apareciam nas pesquisas apresentadas nos artigos encontrados, que é o objetivo central deste trabalho. Essas teorias são importantes para que o professor em sala de aula possa ter uma base teórica com relação aos caminhos a serem trilhados para ensinar os alunos, em particular, àqueles com alguma deficiência visual. No entanto, dos artigos encontrados, nenhum apresenta teoria de aprendizagem explícita.

O levantamento aqui realizado demonstra que esses artigos apresentam vários aspectos importantes, como referencial teórico, metodologia de pesquisa, métodos de coleta de dados e produtos educacionais. Entretanto, a falta de menção a alguma teoria de aprendizagem pode indicar desconhecimento dessas teorias por parte dos autores/professores, o que pode comprometer a pesquisa, principalmente aquelas nas quais materiais didáticos foram construídos e experiências foram realizadas com alunos, pois através delas é possível entender como o desenvolvimento cognitivo dos alunos ocorre. É importante ressaltar que o embasamento em teorias de aprendizagem estabelece uma relação com as ações pedagógicas e mostram como as teorias estudadas questionam os métodos e práticas que os professores aplicam em sala. Esse questionamento tem a intenção de aprofundar as relações entre o aprender e o ensinar, com respaldo nas teorias que explicam tais práticas (NETTO; COSTA, 2017) e, portanto, dão maior fundamento e credibilidade às pesquisas realizadas na área de ensino e educação.

Os mestrados profissionais são responsáveis por grande parte dos produtos educacionais específicos criados no Brasil. A CAPES, por meio da portaria $\mathrm{n}^{\circ} 47$ de 1995, estabelece diretrizes para os mestrados profissionais, onde destaca que:

\begin{abstract}
O estudante deve apresentar trabalho final que demonstre domínio do objeto de estudo e capacidade de expressar-se lucidamente sobre ele. De acordo com a natureza da área e com a proposta do curso, esse trabalho poderá tomar formas como, entre outras, dissertação, projeto, análise de casos, performance, produção artística, desenvolvimento de instrumentos, equipamentos e protótipos. (CAPES, 1995, online).
\end{abstract}

Como resultado final do mestrado, os alunos precisam então desenvolver um produto educacional. Esses produtos são relevantes, pois envolvem os alunos no processo de aprendizagem, sendo assim, importantes para a construção do conhecimento conceitual (NUNES; CHAVES, 2017) com recursos didáticos que podem ter alcance universal, para alunos videntes e não-videntes.

Devido a toda essa importância mencionada, e ao grande incentivo à formação continuada que o MNPEF tem oferecido aos professores da área de física, é que também foram pesquisadas as dissertações dessa modalidade de mestrado. No período em questão, foram encontrados apenas sete trabalhos que tratavam da problemática da inclusão para deficientes visuais no ensino de Física, conforme apresentado no quadro 02.

Nesse quadro, é possível observar que todos os sete trabalhos trazem uma teoria de aprendizagem explícita e também produção de material didático, que são requisitos da dissertação do mestrado profissional. Como essas características já são pré-determinadas pelo programa, é possível perceber que o MNPEF compreende a importância de se embasar 
teoricamente as propostas didáticas a serem desenvolvidas durante o mestrado, mostrando um quadro diferente daquele apresentado com relação aos artigos (quadro 01). As teorias utilizadas com maior frequência foram as de Ausubel, Vygotsky e Piaget, mostrando uma linha de pensamento cognitivista por parte dos alunos de mestrado. Com relação aos conteúdos abordados, três trabalhos estavam voltados à ondulatória (incluindo aqui os estudos de óptica), dois abordaram temas da astronomia, um sobre o eletromagnetismo, e um abordou a estática dos fluidos. Com relação ao produto educacional, seis dos sete trabalhos construíram protótipos táteis, e apenas um levou em conta a audição dos alunos.

As cinco dissertações e três teses encontradas no banco da CAPES também traziam em sua abordagem teórica teorias de aprendizagem que fundamentaram suas propostas, como apresentado no quadro 3, da terceira fase de coleta. Dos oito trabalhos encontrados, seis traziam Vygotsky como referencial (sendo que um deles trazia também outros autores como referencial, como é o caso de Miguel Albert Soler, que traz teorias específicas para ensino de alunos cegos), um trazia a teoria educacional de Paulo Freire e um não traz o texto completo para leitura, por ter sido uma defesa recente, e ainda não se encontrar disponível para consulta.

Além disso, cinco trabalhos traziam a construção de um produto educacional (entre os quais estavam duas teses), e os outros três traziam uma abordagem qualitativa, com entrevistas, observações e estudos de caso. Com relação ao conteúdo trabalhado, dois trabalhos tratavam da física de maneira geral, e não estavam focados em conteúdos específicos, um trabalho era uma análise de formação docente e, portanto, não tratava de conteúdos da física, dois trabalhos versavam sobre mecânica, um sobre ondas, um sobre astronomia e um trabalho de eletromagnetismo, demonstrando um maior alcance no tratamento de tópicos de física. Com relação aos produtos educacionais, três trabalhos trazem materiais táteis e dois trazem sequências multissensoriais.

A partir dessa análise, foi possível construir o quadro 4, que apresenta de uma maneira mais geral essas produções.

Quadro 04 - Teorias de aprendizagem, conteúdos e produtos educacionais

\begin{tabular}{|c|c|c|}
\hline Teoria de aprendizagem & Conteúdo explorado & $\begin{array}{c}\text { Especificidade do } \\
\text { Produto } \\
\text { educacional }\end{array}$ \\
\hline $\begin{array}{c}\text { Sociointeracionismo de Vygotsky - } 9 \\
\text { Aprendizagem significativa de Ausubel - } 2\end{array}$ & Óptica e ondulatória - 6 & \\
Teoria da experimentação de Piaget - 3 & Astronomia - 3 & \\
Multissensorialidade de Soler - 1 & Eletromagnetismo - 2 & Tátil - 12 \\
Teoria Freiriana de ensino - 1 & Mecânica - 2 & Auditivo - 5 \\
Modelos mentais de Johnson-Laird - 1 & Termometria e calorimetria - 1 & \\
\hline
\end{tabular}

Fonte: Elaborado pelos autores. 
É importante ressaltar que a soma total de cada coluna é diferente do número de artigos, pois, por exemplo, um dos artigos tratava de três teorias de aprendizagem, e outro trabalho tratava de três conteúdos de física, e alguns não traziam nem produção didática e nem teorias de aprendizagem. Alguns resultados chamam atenção com relação ao uso das teorias de aprendizagem, como é o caso do uso da teoria sociointeracionista de Vygotsky, que foi a mais utilizada pelos trabalhos pesquisados. Acreditamos que tal escolha esteja relacionada à necessidade de interação do aluno com o produto educacional, que são mais desenvolvidos para alunos deficientes visuais, mas que podem ser também importantes na socialização com os alunos videntes, pois, para Vygotsky, o desenvolvimento não pode ser alcançado sem referência ao contexto social e cultural do aluno, ou seja, a asserção dos processos mentais do indivíduo tem origem em processos sociais (MOREIRA, 1999).

Além disso, outro aspecto destacado são os conteúdos abordados. Diversos conteúdos foram trabalhados, como pode ser constatado no quadro 04, no entanto, nota-se que a parte de óptica e ondulatória apareceram com maior frequência. Acredita-se que isso se dá pela dificuldade que os deficientes visuais poderiam ter com um conteúdo tão visual, o que também pode despertar maior criatividade para o desenvolvimento de recursos que alcancem outros conteúdos não abordados.

Por fim, outro ponto importante a ser discutido é o uso de materiais táteis para uma "adaptação" para uso dos deficientes visuais. Dos 17 produtos educacionais encontrados, apenas 5 levam em conta outro sentido dos alunos, que não o tátil. No entanto, os produtos educacionais devem explorar outros sentidos desses alunos, e também dos alunos videntes, de forma a propiciar um ensino a partir da já mencionada perspectiva do DUA (MEYER; ROSE; GORDON, 2014), que busca reduzir as barreiras do ensino e da aprendizagem ao levar em conta a diversidade dos alunos, respondendo às suas necessidades de maneira geral, ou seja, neste caso, de videntes e não videntes.

A partir desses resultados, que mostram a baixa produção na área de materiais educacionais para deficientes visuais no ensino de física, aliados à produção mais expressiva de materiais exclusivamente táteis, que tentam adaptar o mundo da forma que os videntes enxergam aos não videntes, e ainda associados à falta de um embasamento em uma teoria de aprendizagem que baliza o que será produzido e executado, ficou evidente a necessidade de um esforço conjunto das diversas frentes da educação para se compreender e melhorar o ensino para alunos cegos e de baixa visão.

\section{Considerações finais}

Ao final deste panorama das teorias de aprendizagem e dos produtos educacionais elaborados para atender alunos deficientes visuais, foi possível perceber que existe um número pequeno de pesquisas relacionadas ao ensino de física para alunos com alguma deficiência visual. Outra observação que destacamos é que dessa pequena produção acadêmica, em particular, pela divulgação de periódicos, há pouca ou nenhuma publicação que tenha por base alguma teoria de aprendizagem como norteadora do ensino de física para alunos com deficiência visual ou não.

Vale destacar que a alusão à ausência de teorias de aprendizagem é relativa aos artigos encontrados, pois todas as dissertações pesquisadas continham esse aporte teórico. Observouse que a maior parte desses trabalhos (teses e dissertações) utilizaram a teoria sociointeracionista de Vygotsky. Isso mostra um aspecto positivo da área, que se mostra preocupada com uma aprendizagem efetiva e em perspectiva cognitiva e afetiva dos alunos. 
No entanto, é importante considerar a situação apresentada com relação à ausência de teorias de aprendizagem nos artigos, uma vez que nos programas de pós-graduação em ensino, geralmente, um dos requisitos para as dissertações é justamente esse embasamento teórico educacional. Por outro lado, nos artigos, que são os maiores veiculadores das pesquisas de uma determinada área, as teorias de aprendizagem não são uma exigência, como foi o caso dos trabalhos aqui selecionados. Surge então o seguinte questionamento: será que os pesquisadores não acreditam ser relevante o uso desses fundamentos em suas construções de produtos educacionais e sequências didáticas?

Entretanto, é necessário também deixar claro que o intuito desta pesquisa não é desqualificar os artigos selecionados e sim, contribuir de alguma forma para futuros estudos. Todas as pesquisas encontradas são de elevada importância para o desenvolvimento do ensino e aprendizagem de física para esses alunos.

Também fica aqui destacada a preocupação com uma produção demasiada de materiais táteis, adaptativos de uma concepção vidente, e o apelo ao uso de estratégias que envolvam outros sentidos dos alunos com deficiência visual, bem como estratégias que tragam um Desenho Universal da Aprendizagem, nas quais não sejam necessários materiais e situações "especiais" para deficientes visuais, mas que todos os alunos tenham condições de perceber e compreender, dentro de suas limitações e especificidades.

Como perspectivas futuras, espera-se contribuir para o ensino de deficientes visuais na área de física e ciências, ao se propor produtos e sequências educacionais baseadas explicitamente em fundamentos teóricos de ensino e aprendizagem, em um Desenho Universal da Aprendizagem, e explorando outros sentidos além do tátil.

\section{Referências}

AQUINO, M. N. F. A educação inclusiva na perspectiva da efetivação de direitos: um olhar para o ensino de base na escola estadual Dom Moisés Coelho. 2018. 100f. Trabalho de conclusão de Curso (Graduação em Serviço Social) - Centro de Ciências Jurídicas e Sociais, Universidade Federal de Campina Grande, Cajazeiras/PB. 2018.

AZEVEDO, A. C.; SANTOS, A. C. F. Ciclos de aprendizagem no ensino de física para deficientes visuais. Revista Brasileira de Ensino de Física, v. 36, n. 4, p. 4402-1 - 4402-6, 2014.

BARDIN, L. Análise de conteúdo. São Paulo: Edições 70, 2011.

BRASIL. Lei de Diretrizes e Bases da Educação da Educação Nacional. Brasília, DF, 1996.

BRASIL. Declaração de Salamanca e linha de ação sobre necessidades educativas especiais. 2. ed. Brasília: Corde, 1997.

BRASIL. Instituto Brasileiro de Geografia e Estatística - IBGE. 2010. Disponível em: https://censo2010.ibge.gov.br/. Acesso em: 02 abr. 2020.

CAMARGO, E. P. Ensino de Física e deficiência visual: dez anos de investigação no Brasil. São Paulo: Plêiade, 2008. 
CAPES. Portaria CAPES no 47, de 17 de outubro de 1995. Determina a implantação na Capes de procedimentos apropriados à recomendação, acompanhamento e avaliação de cursos de mestrado dirigidos à formação profissional. Brasília, DF, 1995.

CARLETTO, A. C.; CAMBIAGHI, S. Desenho universal: um conceito para todos. Ebook. MaraGabrili, 2010. Disponível em: https://www.maragabrilli.com.br/wpcontent/uploads/2016/01/universal_web-1.pdf. Acesso em: 22 set. 2020.

CARVAlHO, I. A. F.; BUENO, M. T. O Ensino de Física e as Políticas Públicas da Educação Inclusiva: o que se tem feito? Revista Tecné, Episteme y Didaxis, número extraordinário, p. 1673-1680, 2016.

CORDOVA, H. P. et al. Audiotermômetro: um termômetro para a inclusão de estudantes com deficiência visual. Revista Brasileira de Ensino de Física, v. 40, n. 2, p. e2501- e2505, 2018.

COZENDEY, S. G.; COSTA, M. P. R. Utilizando a audiodescrição como um recurso de ensino. Revista Ibero-Americana de Estudos em Educação, Araraquara, v. 13, n. 03, p. 1164-1186, 2018.

CUNHA, E. L.; DICKMAN, A. G. O estudo da Óptica na modalidade de Educação para Jovens e Adultos (EJA) por meio de uma sequência didática diversificada. Caderno Brasileiro de Ensino de Física, v. 35, n. 1, p. 262-289, 2018.

FERREIRA, N. S. A. As pesquisas denominadas "estado da arte". Educ. Soc. Campinas, v. 23, n. 79, pp. 257-272, 2002.

FERREIRA, A. C.; DICKMAN, A. G. História Oral: um Método para Investigar o Ensino de Física para Estudantes Cegos. Rev. Bras. Ed. Esp., v. 21, n. 2, p. 245-258, 2015.

FIGUEIREDO, R. M.; KATO, E. O. M. Estudos nacionais sobre o ensino para cegos: uma revisão bibliográfica. Rev. bras. educ. espec., v. 21, n.4, p. 477-488, 2015.

FREIRE, P. Pedagogia da Autonomia: Saberes necessários à prática educativa. Rio de Janeiro: Paz e Terra, 1997. 76p.

GASPAR, A.; MONTEIRO, I. C. C. Atividades experimentais de demonstrações em sala de aula: uma análise segundo o referencial da teoria de Vygotsky. Investigações em Ensino de Ciências. v. 10, n. 2, p. 227-254, 2005.

JESUS, R. T.; AMORIM, R. G. G. Uma Proposta de Unidade de Ensino Potencialmente Significativa para Ensinar Física de Partículas por meio de Jogos de Cartas. Revista do Professor de Física, v. 3, n. 1, p. 47-84, 2019.

JOHNSON-LAIRD, P. N. Mental models. Cambridge, MA: Harvard University Press, 1983. LIMA, P. G. Tendências paradigmáticas na pesquisa educacional. São Paulo: Amil, 2003. MACHADO, M. S.; SIQUEIRA, M. R. P.; OLIVEIRA, R. R.; DUARTE, A. C. S. Panorama de publicações no ensino de ciências e educação inclusiva: o que tem sido produzido? Revista Brasileira de Ensino de Ciências e Tecnologia, v. 12, n. 2, p. 395-426, 2019. 
MEYER, A.; ROSE, D. H.; GORDON, D. Universal design for learning: Theory and practice. Wakefield: CAST Professional Publishing, 2014.

MOREIRA, M. A. Teorias de aprendizagem. São Paulo: EPU, 1999.

MOREIRA, M. A.; PINTO, A. O. Dificuldades dos Alunos na Aprendizagem da Lei de Ampère, à Luz da Teoria dos Modelos Mentais de Johnson-Laird. Revista Brasileira de Ensino de Física, v. 25, n. 3, 2003.

NETTO, A. P.; COSTA, O. S. A importância da psicologia da aprendizagem e suas teorias para o campo do ensino-aprendizagem. Revista Fragmentos de Cultura, v. 27, n. 2, p. 216224, 2017.

NUNES, C.; MADUREIRA, I. Desenho Universal para a Aprendizagem: Construindo práticas pedagógicas inclusivas. Revista Da Investigação às Práticas, v. 5, n. 2, p. 126-143, 2015 .

NUNES, P. R.; CHAVES, A. C. L. Ciano Quiz: um jogo digital sobre cianobactérias como instrumento para a educação ambiental no ensino médio. Revista Ciências \& Ideias, v. 7, n. 3, p. 324-349, 2017.

OLIVEIRA, R. R.; MACHADO, M. S.; SIQUEIRA, M. Formamos professores para a educação inclusiva? análise de publicações sobre formação de professores de ciências/biologia. Revista Brasileira de Ensino de Ciências e Tecnologia, v. 10, n. 2, p. 123, 2017.

PREFEITURA DE MARABÁ. Centro de Apoio Pedagógico - CAP. 2019. Disponível em: https://maraba.pa.gov.br/educacao-centro-de-apoio-pedagogico-para-deficientes-visuaisiniciam-as-aulas-no-dia-28-de-janeiro/. Acesso em: 05 abr. 2020.

SALMAZO. R. S.; RODRIGUES, M. I. R. Formação de professores: ensino de física para cegos através de atividades em relevo. Revista Inteiracções, v. 11 n. 39, p. 130-137, 2015.

SANTOS, R. M. Estado da arte e história da pesquisa em educação estatística em programas brasileiros de pós-graduação Campinas. 2015. 348p. Dissertação (Doutorado área de Concentração Ensino e Práticas culturais) - Universidade Estadual de Campinas, Campinas, 2015.

SANTOS, P.; CATARINO, G.; REIS J. C. Formação inicial de professores de física: desafios de mudança do sistema educacional brasileiro. In: CONGRESO INTERNACIONAL SOBRE INVESTIGACIÓN EN DIDÁCTICA DE LAS CIENCIAS, 5., 2017, Sevilla. Anais [...]. Sevilla, 2017. p. $2589-2593$.

SANTOS, J. F. L.; BRITO, M. F. G. Educação inclusiva: modelo didático de peixe para alunos com deficiência visual no ensino de ciências e biologia. Revista Ciências \& Ideias, v. 10, n. 3, p. $206-223,2019$.

SILVA, A. C.; SANTOS, C. A. Lâminas em alto-relevo para ensinar fenômenos ondulatórios a deficientes visuais. Revista Brasileira de Ensino de Física, v. 40, n. 4, p. e5406-1 - e5406 7, 2018. 
SOARES, E. L.; VIÇOSA, C. S. C. L; TAHA, M. S.; FOLME, V. A presença do lúdico no ensino dos modelos atômicos e sua contribuição no processo de ensino aprendizagem.

Revista Góndola, Enseñanza y Aprendizaje de las Ciencias, v. 12, n. 2, p. 69-80, 2017.

SOLINO, A. P.; GEHLEN, S. T. O papel da problematização freireana em aulas de ciências/física: articulações entre a abordagem temática freireana e o ensino de ciências por investigação. Ciência \& Educação, v. 21, n. 4, p. 911-930, 2015.

TORRES, J. P.; MENDES, E. G. Avaliação de um kit didático que reproduz tatilmente ilustrações no Ensino de Física. Revista Educação Especial, v. 32, p. e35/ 1-14, 2019.

UNICEF. Declaração Mundial sobre Educação para Todos (Conferência de Jomtien 1990. Tailândia, 1990.

VOOS, I. C.; FERREIRA, G. K. Acessibilidade para estudantes cegos e baixa visão: análise dos objetos educacionais digitais de física. Revista Educação Especial, v. 31, n. 60, p. 21-34, 2018 .

Recebido em dezembro de 2020.

Aprovado em maio de 2021. 